\title{
Self-Assembly of a Virus-Mimicking Nanostructure System for Efficient Tumor-Targeted Gene Delivery
}

\author{
LIANG XU, ${ }^{1}$ PETER FREDERIK, ${ }^{2}$ KATHLEEN F. PIROLLO,${ }^{1}$ WEN-HUA TANG,${ }^{1}$ ANTONINA RAIT, ${ }^{1}$ \\ LAI-MAN XIANG,${ }^{1}$ WEIQUN HUANG,${ }^{1}$ IDALIA CRUZ,${ }^{1}$ YUZHI YIN,${ }^{1}$ and ESTHER H. CHANG ${ }^{1}$
}

\begin{abstract}
Molecular therapy, including gene therapy, is a promising strategy for the treatment of human disease. However, delivery of molecular therapeutics efficiently and specifically to the target tissue remains a significant challenge. A human transferrin (Tf)-targeted cationic liposome-DNA complex, Tf-lipoplex, has shown high gene transfer efficiency and efficacy with human head and neck cancer in vitro and in vivo (Xu, L., Pirollo, K.F., Tang, W.H., Rait, A., and Chang, E.H. Hum. Gene Ther. 1999;10:2941-2952). Here we explore the structure, size, formation process, and structure-function relationships of Tf-lipoplex. We have observed Tf-lipoplex to have a highly compact structure, with a relatively uniform size of 50-90 $\mathbf{~ m}$. This nanostructure is novel in that it resembles a virus particle with a dense core enveloped by a membrane coated with Tf molecules spiking the surface. More importantly, compared with unliganded lipoplex, Tf-lipoplex shows enhanced stability, improved in vivo gene transfer efficiency, and long-term efficacy for systemic p53 gene therapy of human prostate cancer when used in combination with conventional radiotherapy. On the basis of our observations, we propose a multistep self-assembly process and Tf-facilitated DNA cocondensation model that may provide an explanation for the resultant small size and effectiveness of our nanostructural Tf-lipoplex system.
\end{abstract}

\section{OVERVIEW SUMMARY}

Our Tf-lipoplex system shows enhanced stability, improved in vivo gene transfer efficiency, and long-term efficacy for systemic p53 gene therapy of human prostate cancer when used in combination with conventional radiotherapy. We have found Tf-lipoplex molecules to have a highly compact structure with a relatively uniform size of $50-90 \mathrm{~nm}$. This novel nanostructure resembles the structure of a virus particle with a dense core enveloped by a membrane coated with Tf molecules spiking the surface. A multistep self-assembly process and Tf-facilitated DNA cocondensation model is proposed on the basis of our observations and likely contributes to the small size and effectiveness of the Tf-lipoplex nanostructure.

\section{INTRODUCTION}

$\mathbf{M}$ OLECULAR THERAPY, including gene therapy, is a promising strategy for the treatment of human disease. How- ever, delivery of molecular therapeutics efficiently and specifically to the target tissue remains a significant challenge (Marshall et al., 2000). Progress has been made toward developing nonviral, pharmaceutical formulations of genes for in vivo human therapy, particularly cationic liposome-mediated gene transfer systems (Pirollo et al., 2000). However, these cationic liposome-DNA complexes (lipoplexes) suffer from low gene transfer efficiency, large particle size, poor stability, and, more importantly, lack of targeting capability (Pirollo et al., 2000). Current efforts at tumor targeting of lipoplexes for targeted gene delivery and systemic gene therapy directed by inclusion of a ligand in the complex are encouraging (L. Xu et al., 2001). To improve the gene transfer efficiency and tumor targetability of lipoplexes, we incorporated human transferrin (Tf) into the complex to form Tf-lipoplex (L. Xu et al., 1997, 1999a). Tf-lipoplex has demonstrated high efficiency in tumor-targeted gene delivery and long-term therapeutic efficacy in systemic p53 gene therapy for both human head and neck cancer (L. Xu et al., 1999a) and prostate cancer (see below).

There has been an increasing number of publications on the structure of cationic liposome-DNA complexes or lipoplexes

\footnotetext{
${ }^{1}$ Department of Oncology, Lombardi Cancer Center, Georgetown University Medical Center, Washington, D.C. 20007.

${ }^{2}$ Electron Microscopy Unit, Department of Pathology, University of Maastricht, 6200 MD Maastricht, The Netherlands.
} 
(Battersby et al., 1998; Dan, 1998; Sternberg et al., 1998; Huebner et al., 1999; Kennedy et al., 2000; Lin et al., 2000). Several models have been proposed, largely on the basis of electron microscopy (EM), small-angle X-ray scattering (SAXS), and atomic force microscopy (AFM) studies (Radler et al., 1997; Dan, 1998; Kawaura et al., 1998; Koltover et al., 1999; Kennedy et al., 2000). A widely cited model in the literature is the lamellar $\mathrm{L}_{\alpha}{ }^{\mathrm{C}}$ structure, in which the DNA helix is sandwiched between cationic lipid bilayers in ordered two-dimensional arrays (Lasic et al., 1997; Radler et al., 1997; Koltover et al., 1998; Lin et al., 2000). However, the structure and formation process of the much more efficient and efficacious Tf-lipoplex has yet to be elucidated. Using cryoelectron microscopy (cryo-EM), negative-staining EM, and photon correlation spectroscopy, we have observed a highly compact structure of Tf-lipoplex with a relatively uniform size of 50-90 nm. This nanostructure is novel in that its structure resembles that of a virus particle (e.g., influenzavirus or herpesvirus) with a dense core enveloped by a membrane coated with Tf molecules spiking the surface. Here we attempt to elucidate the mechanism by which the Tf-coated cationic liposomes could efficiently condense DNA into this virus-mimicking nanostructure and to understand how the Tf molecules are involved in the self-assembly process of the Tf-lipoplex. On the basis of our observations and the above-mentioned lipoplex structure models, we propose a multistep self-assembly process and Tf-facilitated DNA cocondensation model that may provide an explanation for the resultant small size and effectiveness of our nanostructure Tf-lipoplex system.

\section{MATERIALS AND METHODS}

\section{Preparation of Tf-lipoplexes}

Cationic liposomes (Lip) consisting of dioleoyl trimethylammonium propane (DOTAP) and dioleoyl phosphatidylethanolamine (DOPE) (Avanti Polar Lipids, Alabaster, AL) at a 1:1 molar ratio were prepared either by sonication or ethanol injection as previously described (L. Xu et al., 1997, 1999a, 2001). Tf-Lip-DNA was prepared according to the in vivo formulation described previously (L. Xu et al., 1999a). Briefly, for a typical preparation with optimized in vivo formulation, $25 \mu \mathrm{l}$ of Tf $(5 \mathrm{mg} / \mathrm{ml}$, iron-saturated holo-transferrin; Sigma, St. Louis, MO) and $50 \mu \mathrm{l}$ of Lip ( $2 \mathrm{~m} M$ total lipids) plus $75 \mu \mathrm{l}$ of water were mixed in a polypropylene tube and incubated for 5-15 min at room temperature with frequent rocking. Ten micrograms of plasmid DNA in $120 \mu \mathrm{l}$ of $20 \mathrm{~m} M$ HEPES buffer, pH 7.4, was added to the tube, mixed immediately and thoroughly, and incubated for $20 \mathrm{~min}$ at room temperature with frequent rocking. Thirty microliters of $50 \%$ dextrose solution was then added to the tube. The final DNA:lipid:Tf ratio was 1:10:12.5 $(\mu \mathrm{g} / \mathrm{nmol} / \mu \mathrm{g})$. The HEPES buffer can be replaced by pure water.

\section{In vitro transfection}

For optimization of Tf-liposome-DNA complex preparation and transfection conditions, the quantitative $\beta$-galactosidase colorimetric assay was employed as described previously (L.
Xu et al., 1997, 1999a). DU145 cells $\left(1 \times 10^{4}\right)$ were plated in each well of a 96-well plate. Twenty-four hours later, the cells were washed once with Eagle's minimal essential medium (EMEM) without serum or antibiotics and $100 \mu \mathrm{l}$ of transfection solution containing various amounts of $\mathrm{Tf}$-liposomepCMVb as well as lipoplex without Tf was added to each well. After $5 \mathrm{hr}$ of transfection at $37^{\circ} \mathrm{C}, 100 \mu \mathrm{l}$ of EMEM containing $20 \%$ fetal bovine serum was added to each well. Forty-eight hours later, the cells were washed once with phosphate-buffered saline (PBS) and lysed in $50 \mu \mathrm{l}$ of $0.1 \mathrm{M}$ Tris (pH 7.5) containing $0.1 \%$ Triton $\mathrm{X}-100$ and $1 \mathrm{mM} \mathrm{MgCl}$. The cell lysates were treated with $100 \mu \mathrm{l}$ of $150 \mu M o$-nitrophenyl- $\beta$-D-galactopyranoside in $20 \mathrm{~m} M$ Tris ( $\mathrm{pH} 7.5$ ) containing $1 \mathrm{mM} \mathrm{\textrm {MgCl } _ { 2 }}$ and $450 \mathrm{~m} M 2$-mercaptoethanol at $37^{\circ} \mathrm{C}$ for $1 \mathrm{hr}$. The reaction was stopped by the addition of $1 M \mathrm{Na}_{2} \mathrm{CO}_{3}(150 \mu \mathrm{l} /$ well $)$. The absorbance was determined at $405 \mathrm{~nm}$. Purified $\beta$-galactosidase (Boehringer, Indianapolis, IN) was used as standard. The results were expressed as milliunits $(\mathrm{mU})$ of $\beta$-galactosidase equivalent per milligram of total protein.

\section{In vivo efficacy study}

Xenograft tumors were induced by the subcutaneous injection of $6 \times 10^{6}$ DU145 cells in Matrigel basement membrane matrix (Collaborative Biomedical Products, Bedford, MA) into the lower back, above the tail, of 4- to 6-week-old female athymic nude mice. Mice bearing tumors of $\sim 70$ to $100 \mathrm{~mm}^{3}$ were injected, via the tail vein, with Tf-Lip-p53 or Tf-Lip-pVec at $10 \mu \mathrm{g}$ of DNA per $0.3 \mathrm{ml}$ per injection, twice weekly for a total of 10 injections, and the tumors only were exposed to 2.0Gy fractionated doses of $\gamma$ radiation (total, 40 Gy) (L. Xu et al., 1999a). For comparison, control groups included a group of untransfected mice with or without radiation, as well as a group of mice with Tf-Lip-p53 injection receiving no radiation. Each experimental group consisted of five animals. The tumor sizes were measured weekly in a blinded manner. All animal experiments were performed in accordance with Georgetown University institutional guidelines for the care and use of animals.

\section{Filtration of Tf-lipoplexes}

Tf-lipoplex was prepared as described above, using DNA of pCMVb, a plasmid carrying the Escherichia coli $\beta$-galactosidase gene. Nontargeted lipoplex was prepared similarly but without Tf. Tf-lipoplex and lipoplex were filtered serially through polycarbonate membranes (Nuclepore, Pleasanton, CA) starting with a pore size of $400 \mathrm{~nm}$, followed by 200, 100, 80 , and $50 \mathrm{~nm}$. The membranes were mounted in $25-\mathrm{mm}$ stainless steel filter holders (Millipore, Bedford, MA). After each filtration, samples were collected and either the $\mathrm{OD}_{600 \mathrm{~nm}}$ was determined or the DNA concentration was measured to calculate the percentages of each pass-through. To measure DNA concentrations, a PicoGreen double-strandedDNA (dsDNA) kit (Molecular Probes, Eugene, OR) was used with samples lysed by $0.5 \%$ Triton $\mathrm{X}-100$ (Sigma). In vitro transfection studies were carried out as previously described (L. Xu et al., 1997, 1999a,b). For p53-mediated cytotoxicity studies, DU145 cells in a 96-well culture plate were treated with serially filtered Tf-Lip-p53, the same as in in vitro transfection. Forty-eight hours after treatment, the XTT cytotoxicity assay was per- 
formed and the $\mathrm{ED}_{50}$, that is, the effective dose of DNA (ng/well) that kills $50 \%$ of cells, was calculated (L. Xu et al., 2001).

\section{Photon correlation spectroscopy}

The sizes and $\zeta$ potentials of Tf-liposomes and Tf-lipoplexes were measured by photon correlation spectroscopy, also known as dynamic light scattering (Y. Xu et al., 1999), using a Zetasizer 3000HS (Malvern, Southboro, MA). The measurements were performed according to the manufacturerinstructions with the following settings: temperature, $25^{\circ} \mathrm{C}$; scattering angle, $90^{\circ}$; analysis mode, CONTIN by number. The results are presented as the mean \pm the standard deviation of at least three preparations; each preparation was measured three times.

\section{Electron microscopy analysis of Tf-Lipoplex}

Cryoelectron microscopy (cryo-EM) was performed as described (Lasic et al., 1997; Templeton et al., 1997; Y. Xu et al., 1999). Briefly, a grid was dipped in and withdrawn from a sample vial, blotted with filter paper, and by a guided drop vitrified in melting ethane. Specimen preparation was done in a controlled environment (temperature, humidity) with a fully automated (PCcontrolled) system. The vitrified specimens were transferred to a cryoholder (operating at $-170^{\circ} \mathrm{C}$ ) and observed in a Philips (Mt. Vernon, NY) CM12 microscope at $120 \mathrm{kV}$ under low-dose conditions. Transmission electron microscopy with $4 \%$ uranium acetate negative staining was carried out as described (Dan, 1998). A JEOL (Akishima, Japan) 1200EX or JEOL 100S was used in this study. The liposome samples on the grids were prepared, freshly stained, and observed within $1 \mathrm{hr}$.

\section{RESULTS}

\section{Optimization of Tf-Lipoplex}

We have previously shown that the tumor suppressor gene p53 delivered by Tf-lipoplex optimized for head and neck cancer could, in combination with conventional radiotherapy, result in long-term tumor regression in a xenograft tumor model (L. Xu et al., 1999a). To optimize the Tf-lipoplex formulation for gene delivery to human prostate cancer cells, a quantitative $\beta$-galactosidase colorimetric assay (L. Xu et al., 1999a) was employed. Human prostate cancer cell line DU145 was used as a model. The tumor cells were transfected with Tf-lipoplex prepared at various DNA:lipid:Tf ratios, using a plasmid containing the $E$. coli $\beta$-galactosidase gene as the reporter gene (pCMVb), as previously described for the in vivo formulation (L. Xu et al., 1997, 1999a). Figure 1a shows that transferrin significantly enhanced the transfection efficiency of cationic liposomes. Interestingly, the optimal formulation for prostate cancer cells has a DNA:lipid:Tf ratio of $1 \mu \mathrm{g}: 10 \mathrm{nmol}: 12.5 \mu \mathrm{g}$, the same as that optimized for the human head and neck cancer model (L. Xu et al., 1999a). For prostate cancer cell line DU145, the transfection efficiency is comparable to that of the head and neck cancer cell line JSQ-3, with an in vitro efficiency of $60-70 \%$ and in vivo efficiency of $20-30 \%$, as we have reported previously (L. Xu et al., 1997, 1999a). This optimized Tf-lipoplex is quite stable. Storage under nitrogen at $4^{\circ} \mathrm{C}$ for 1 month did not result in any significant loss of in vitro transfection activity (Fig. 1b).

\section{Tf-Lipoplex-mediated systemic gene delivery to human prostate cancer xenografts}

To evaluate in vivo tumor-targeted gene delivery, plasmid pGFP, containing a reporter gene encoding green fluorescent protein, was complexed in Tf-lipoplex, nontargeted lipoplex (no targeting ligand), or bovine serum albumin (BSA)-complexed lipoplex (BSA-lipoplex). BSA has a similar, although slightly lower molecular mass $(69 \mathrm{kDa})$ than $\mathrm{Tf}(77 \mathrm{kDa})$ and was used here as a negative control to demonstrate ligand-specific targeting. The complexes were injected via the tail vein (32 $\mu \mathrm{g}$ of DNA per $0.6 \mathrm{ml}$, three injections within $24 \mathrm{hr}$ ) into nude mice bearing DU145 subcutaneousxenografts. Forty-eight hours after the first injection, the tumors and major organs were excised for Western analysis of GFP expression as previously described (L. Xu et al., 1999a,b). As shown in Fig. 2a, the tumor in the Tf-lipoplex-injected mouse showed significant expression of the GFP gene whereas no expression was observed in the tumors of the animals injected with lipoplex or BSA-lipoplex. The Tf-lipoplex-mediated systemic gene delivery was tumor specific in that the liver and lung showed no obvious gene expression (Fig. 2a). The same was true for other normal tissues and organs (data not shown). Using histochemical staining in a study of head and neck cancer xenograft tumors treated with Tf-lipoplex, we have previously shown that expression of the $\beta$-galactosidase reporter gene was evident only in the tumor cells, whereas normal organs showed only staining of the macrophages (L. Xu et al., 1999a).

To assess Tf-lipoplex-mediated p53 gene delivery and expression, nude mice bearing DU145 subcutaneous tumors were injected with Tf-Lip-p53 via the tail vein $(20 \mu \mathrm{g}$ per $0.6 \mathrm{ml}$, four injections within $32 \mathrm{hr}$ ). The tumors and major organs were excised $48 \mathrm{hr}$ after the first injection for Western analysis of exogenous p53 gene expression as previously described (L. Xu et al., 1999a,b). As shown in Fig. 2b, the tumor in the Tf-Lip-p53-injected mouse showed a high level of exogenous wild-type p53 expression. In contrast, no significant exogenous p53 expression was found in tumors from the mouse injected with nontargeted Lip-p53. Consistent with the GFP study, intravenous injection of Tf-Lip-p53 led to only limited exogenous p53 expression in liver, lung, and spleen (Fig. 2b). Our previous study (L. Xu et al., 1999a) has shown that only macrophages such as histiocytes of the lung or the Kupffer cells of the liver of the animals intravenously injected with Tf-lipoplex showed transgene expression, whereas the lung alveolar cells and the hepatocytes remained negative. Both GFP and p53 experiments were repeated at least three times with representative results shown in Fig. $2 a$ and $b$.

\section{Efficacy of systemic p53 gene therapy in human prostate cancer animal model}

To determine the in vivo efficacy of Tf-lipoplex-mediated p53 gene therapy, the DU145 subcutaneous xenograft tumor model was also employed (L. Xu et al., 1999b). Nude mice bearing tumors of 70 to $100 \mathrm{~mm}^{3}$, equivalent to an $\sim 1-\mathrm{lb}$ tumor in a $200-1 b$ person, were injected, via the tail vein, with Tf-Lip-p53, Tf-Lip-pVec (plasmid vector without p53), or 
$\mathbf{a}$

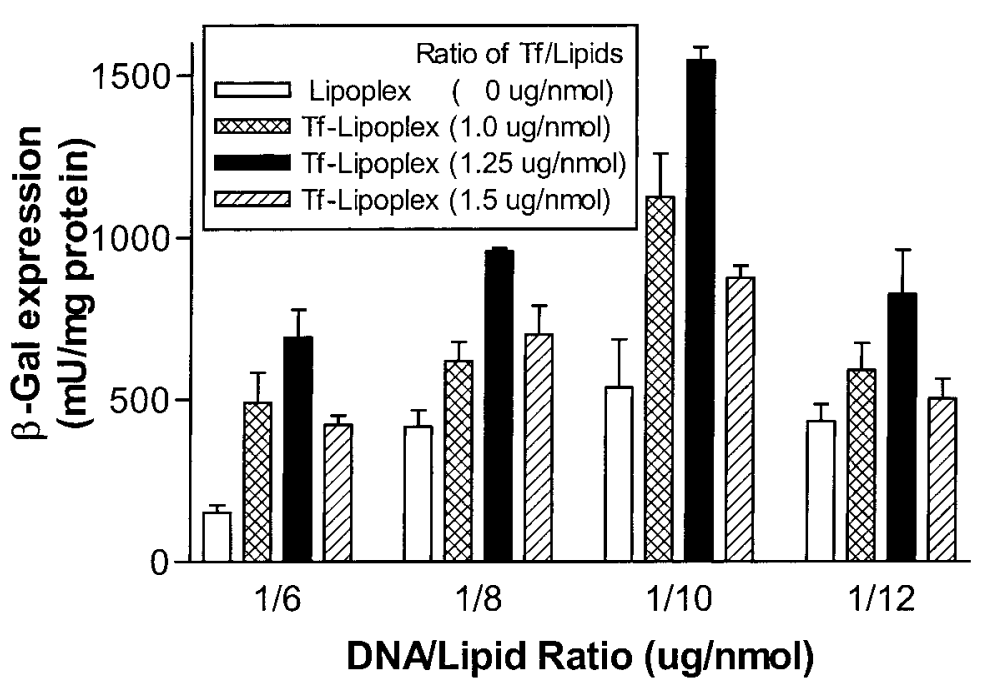

b

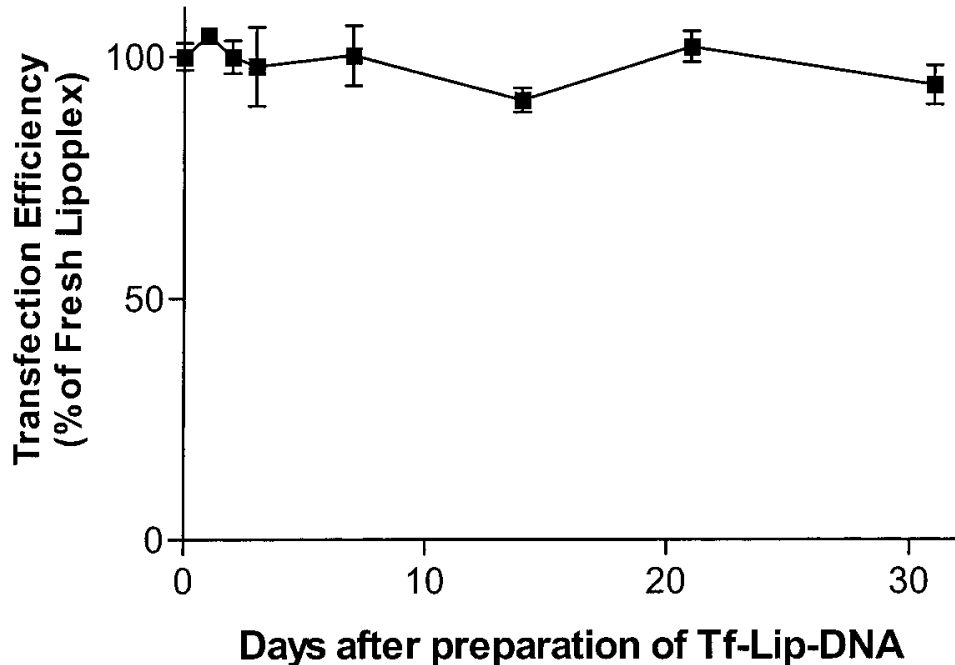

FIG. 1. Optimization of Tf-lipoplex formulation for human prostate cancer cell line DU145. (a) Human prostate cancer DU145 cells were transfected with Tf-lipoplex containing pCMVb at various DNA:lipid:Tf ratios, as previously described (L. Xu et al., 1997, 1999a). The optimized formulation for DU145 cells is a DNA:lipid:Tf ratio of $1 \mu \mathrm{g}: 10 \mathrm{nmol}: 12.5 \mu \mathrm{g}$. (b) Stability of the optimized Tf-lipoplex formulation. Tf-lipoplex preparations were stored under nitrogen at $4^{\circ} \mathrm{C}$ for various time periods and assayed for DU145 transfection as in (a). Tf-lipoplex with the optimal formulation is stable for up to 1 month in vitro.

nontargeted Lip-p53, at $10 \mu \mathrm{g}$ of DNA per $0.3 \mathrm{ml}$ per injection, twice weekly for a total of 10 injections. The tumor area only was exposed to 2.0-Gy fractionated doses of $\gamma$ radiation (total, 40 Gy), as previously described (L. Xu et al., 1999a). As shown in Fig. 3, Tf-lipoplex showed improved efficacy in systemic p53 gene therapy of human prostate cancer as compared with untargeted Lip-p53. More significantly, when combined with radiation, the Tf-Lip-p53-treated group exhibited complete tumor regression and showed no signs of recurrence 6 months after treatment $(p<0.001$, Student's $t$ test). This is consistent with an earlier report of the long-term efficacy of Tf-Lip-p53 radiosensitization in a head and neck cancer animal model (L. Xu et al., 1999a).

\section{Tf-Lipoplex particle size-function relationship}

To understand why the inclusion of $\mathrm{Tf}$ in the lipoplex particles results in such a profound effect on tumor-targeted gene delivery efficiency and efficacy, we performed studies to characterize this optimized in vivo Tf-lipoplex formulation. First, to examine the effect of Tf-lipoplex particle size on gene transfection efficiency and p53-mediated tumor cell killing, Tf-lipoplex, as well as nontargeted lipoplex, were serially filtered through polycarbonatemembranes with pore sizes of 400 , $200,100,80$, and $50 \mathrm{~nm}$. After each filtration, the percentage of each pass-through was determined either by DNA concentration or $\mathrm{OD}_{600 \mathrm{~nm}}$ (see Materials and Methods). As shown in 


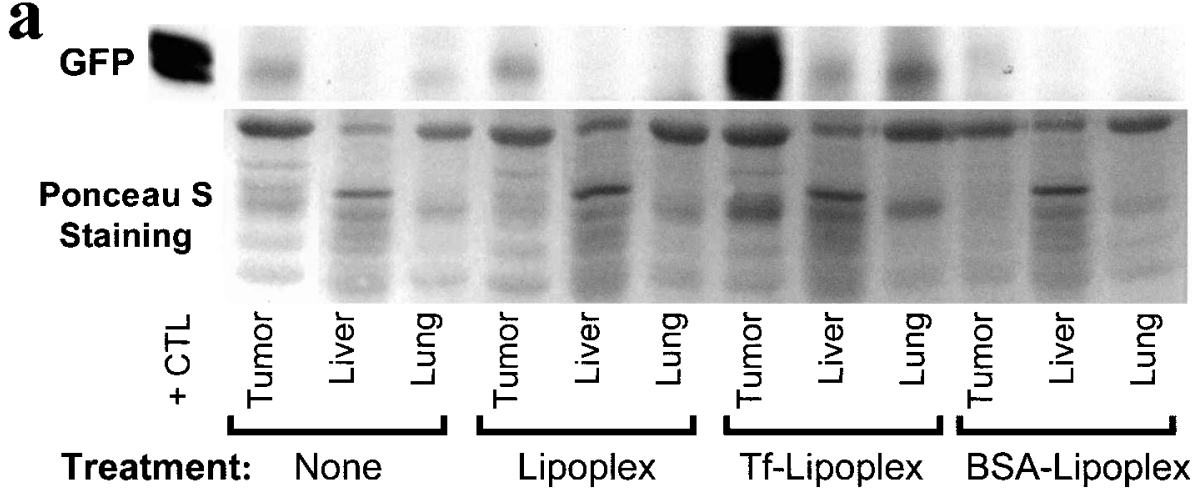

b

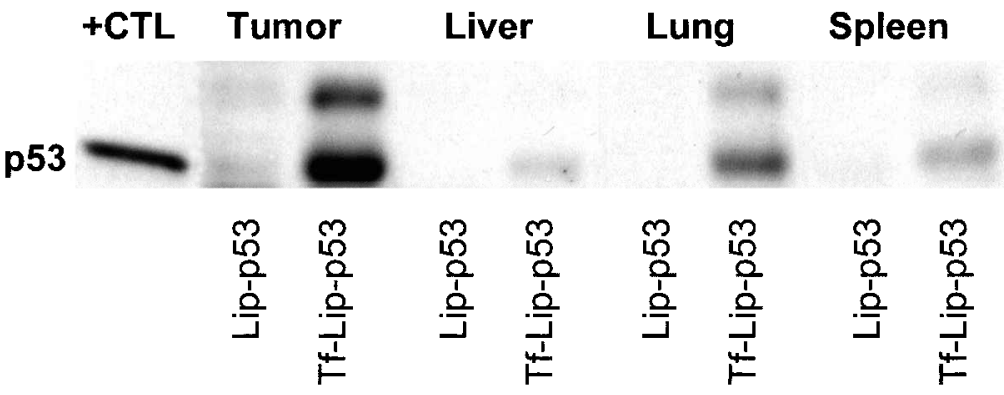

FIG. 2. In vivo systemic gene delivery and expression by optimized Tf-lipoplex. (a) Tumor-targeted delivery of GFP gene. Lipoplex, Tf-lipoplex, or BSA-lipoplex was injected via the tail vein (three injections of $32 \mu \mathrm{g}$ of DNA within $24 \mathrm{hr}$ ) into nude mice bearing human prostate cancer DU145 subcutaneous xenografts. Forty-eight hours after the first injection, the tumors and major organs were excised for Western analysis of GFP expression. A total of $80 \mu \mathrm{g}$ of protein was loaded per lane and an antiGFP monoclonal antibody (BAbCO, Berkeley, CA) was used for Western analysis. We observed that actin and GAPDH were expressed at different levels between human tumor xenografts and mouse organs. Therefore, to demonstrate that the same amount of protein was loaded in each lane, a Ponceau S kit (Sigma) was employed to stain the membrane. The tumor in the Tf-lipoplexinjected mouse showed significant GFP expression whereas no expression was observed in tumors in the animals injected with lipoplex or BSA-lipoplex. + CTL, Positive control, DU145 cells transfected with Tf-Lip-pGFP. (b) Systemic p53 gene delivery and expression, as described in Materials and Methods. A total of $80 \mu \mathrm{g}$ of protein was loaded per lane. The mouse intravenously injected with Tf-Lip-p53 (four injections of $20 \mu \mathrm{g}$ within $32 \mathrm{hr}$ ) showed high-level exogenous wild-type p53 expression in tumor whereas only limited expression occurred in mouse organs including liver, lung, and spleen. + CTL, Positive control, DU145 cells transfected with Tf-Lip-p53.

Fig. 4a, $80 \%$ of particles in the optimal Tf-lipoplex formulation easily passed through the $100-\mathrm{nm}$ pore size filter, $70 \%$ passed through the $80-\mathrm{nm}$ pore size filter, and $60 \%$ passed through the $50-\mathrm{nm}$ pore size filter. The $\mathrm{OD}_{600 \mathrm{~nm}}$ showed results comparable to the DNA concentration results (data not shown). However, lipoplex without Tf could pass through the $100-n m$ pore size filter only after applying much greater pressure. This is consistent with lipoplex sizes of 150-400 nm as reported by other groups (Huebner et al., 1999; Lin et al., 2000). Although transfection efficiency for all particle sizes is DNA dose dependent, in in vitro transfection using $\mathrm{pCMVb}$ as the reporter gene (Fig. 4b), at a DNA dose of $0.05 \mu \mathrm{g} / \mathrm{well}$, the 50 $\mathrm{nm}$ pore size-filtered Tf-lipoplex showed a 3-fold higher transfection activity than the nonfiltered Tf-lipoplex. The order of transfection efficiency from these data was found to be as follows: $50-\mathrm{nm}$ filtered $>80-\mathrm{nm}$ filtered $>100-\mathrm{nm}$ filtered $>$ nonfiltered. A similar order was also observed in Tf-lipoplexdirected,tumor suppressorgene p53-mediated tumor cell killing that was measured as the $\mathrm{ED}_{50}$, the effective dose of DNA (ng/well) that kills $50 \%$ of cells. The Tf-Lip-p53 ED 50 order was found to be as follows: $50-\mathrm{nm}$ filtered $=80-\mathrm{nm}$ filtered $\left(\mathrm{ED}_{50}=25 \mathrm{ng}\right)>100-\mathrm{nm}$ filtered $(64 \mathrm{ng})>200-\mathrm{nm}$ filtered $(66 \mathrm{ng})>400-\mathrm{nm}$ filtered $(82.5 \mathrm{ng})>$ nonfiltered $(112.5 \mathrm{ng})$. On the basis of the $\mathrm{ED}_{50}$, the 50 - to 80 -nm pore size-filtered particles are significantly more effective than the nonfiltered particles. These results demonstrate that the smaller sized particles have better biological activity. Approximately $80 \%$ of the particles are smaller than $100 \mathrm{~nm}$. Consequently, to facilitate sample preparation, the Tf-lipoplex particles used in in vivo studies were not filtered.

We further measured the particle size and $\zeta$ potential of the Tf-lipoplex particles by dynamic laser light scattering (DLS; Y. Xu et al., 1999). The cationic liposome (Lip) itself has a diameter of $28.7 \pm 5.1 \mathrm{~nm}$ (mean $\pm \mathrm{SD}, n=7$ batches) and a net positive charge of $+61.7 \pm 3.5 \mathrm{mV}(n=11)$. Lip-DNA lipoplex has a size of $150-350 \mathrm{~nm}$ and $\zeta$ potential of $+30-35$ 


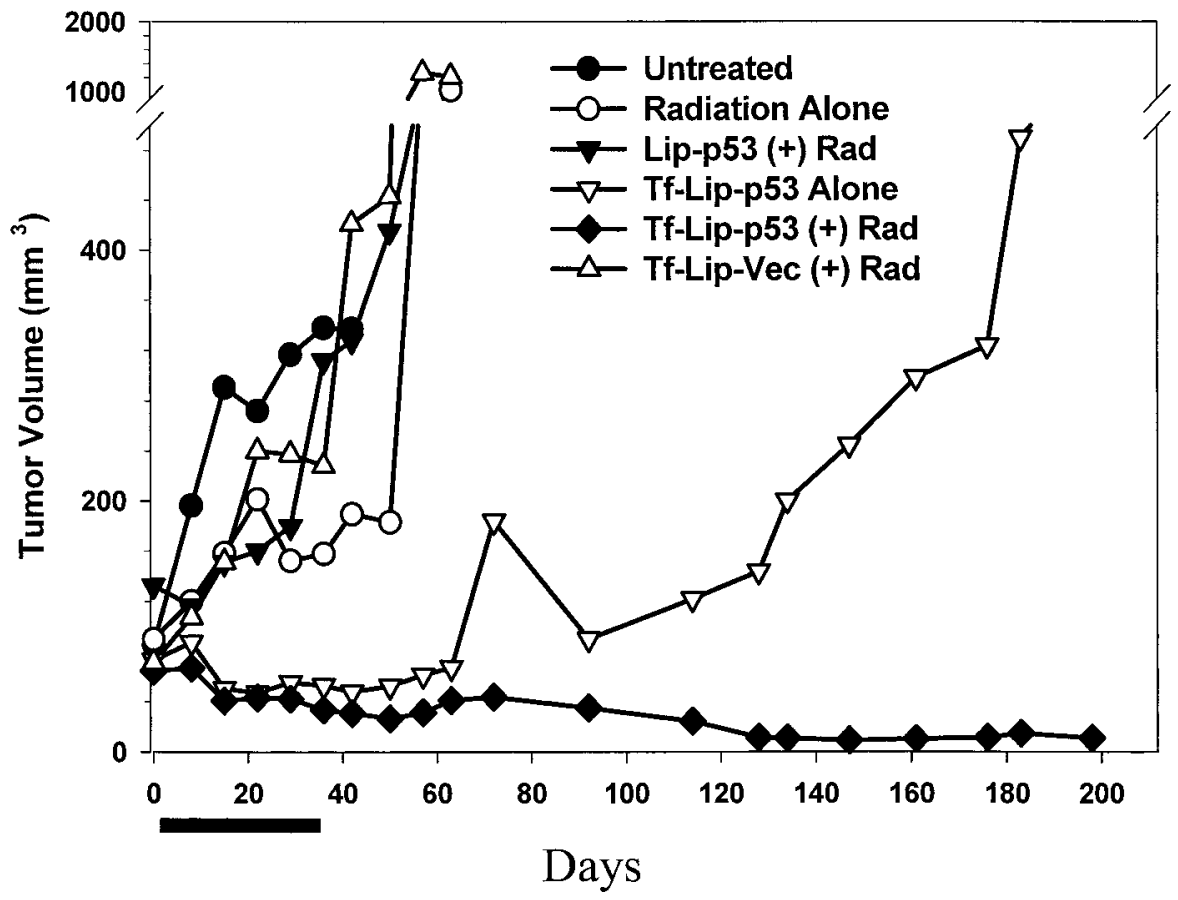

FIG. 3. Effect of the combination of Tf-Lip-p53 and radiation treatment on DU145 xenografts in vivo. Nude mice bearing tumors of $\sim 70$ to $100 \mathrm{~mm}^{3}$ were injected, via the tail vein, with Tf-Lip-p53, Tf-Lip-pVec (plasmid vector without p53), or nontargeted Lip-p53, $10 \mu \mathrm{g}$ of DNA per $0.3 \mathrm{ml}$ per injection, twice weekly for a total of 10 injections, and the tumors only were exposed to 2.0-Gy fractionated doses of $\gamma$ radiation (total, $40 \mathrm{~Gy}$ ), as previously described (L. Xu et al., 1999a). There were five nude mice per group. The horizontal bar indicates the duration of treatment. The standard error for the combination group was negligible. The Tf-Lip-p53 plus radiation-treated group exhibited complete tumor regression and showed no signs of recurrence even 6 months after treatment.

$\mathrm{mV}$. Tf-coated liposome, Tf-Lip, has a size of $30.6 \pm 4.8 \mathrm{~nm}$ and a net positive charge of $+45.3 \pm 1.3 \mathrm{mV}$. When complexed with plasmid DNA, the size of Tf-lipoplex particles is $63.8 \pm$ $6.3 \mathrm{~nm}$, with a close to neutral surface charge $(\zeta$ potential, $+2.3 \pm 1.9 \mathrm{mV} ; n=14)$. The DLS results confirmed that the vast majority of $\mathrm{Tf}$-lipoplex particles are between 50 and 90 $\mathrm{nm}$ in diameter. It is worth noting that $50-\mathrm{nm}$ pore size-filtered Tf-lipoplex has a diameter of 60-65 $\mathrm{nm}$ as determined by DLS, indicating that $\mathrm{Tf}$-lipoplex has a certain degree of flexibility permitting it to pass through the $50-\mathrm{nm}$ pore size filter.

These results indicate that these small (50- to 90-nm) particles are likely to be the population accounting for the high efficiency and efficacy of Tf-lipoplex-mediated gene delivery. This particle size range is consistent with studies of tumor microvasculature showing that small particles effectively pass through blood vessels via transendothelial cell pores $<100 \mathrm{~nm}$ in diameter (Feng et al., 1997). The results also imply that one of the consequences of including $\mathrm{Tf}$ in Tf-lipoplex is the decrease in particle size and thus improved efficiency.

\section{Ultrastructure of Tf-Lipoplex}

How can we account for the apparent decrease in size and increase in efficiency of lipoplex when it contains Tf? Using ${ }^{125}$ I-labeled Tf and Sepharose-4B chromatography, it has been previously demonstrated (Cheng, 1996) that Tf can associate with cationic liposomes, presumably through electrostatic in- teraction. When mixed, negatively charged $\mathrm{Tf}$ will bind to cationic liposomes, coating the surface of the liposomes. To attempt to elucidate structural changes associated with the formation of $\mathrm{Tf}$-lipoplex, we examined the ultrastructure of Tf-lipoplex by cryoelectron microscopy (Gustafsson et al., 1995; Templeton et al., 1997). DOTAP:DOPE liposomes are typical small (20- to 30-nm) unilamellar vesicles (SUVs; see Fig. 5a). When mixed with Tf, a 2- to 3-nm layer of Tf coating can be seen protruding from the bilayer surface (Fig. $5 \mathrm{~b}$ and insets). After complexing with plasmid DNA according to the optimized in vivo formulation, the resulting Tf-lipoplex showed a uniformly condensed core structure surrounded by a Tf-coated membrane. The Tf-lipoplex particles have a diameter of 50-90 $\mathrm{nm}$, with the majority being approximately $60-75 \mathrm{~nm}$ in diameter (Fig. 5c-h). Tf-lipoplex was found to be of similar structure and size irrespective of the method of SUV preparation, that is, by sonication (Fig. 5c-e) or by ethanol injection (Fig. $5 \mathrm{f}-\mathrm{h})$. High-magnification images of the Tf-lipoplex in Fig. 5d and Fig. 5g1 and g2 (enlarged from Fig. 5g) show a condensed core structure surrounded by a membrane coated with Tf spikes on the surface. Two types of particles were observed by cryoEM: light particles with a bright center (Fig. 5c-e) and dark particles with a high electron density center (Fig. 5c and g). The dark particles dominate the Tf-lipoplex population (more than $80-90 \%$; Fig. 5c, g, and h). We do not as yet understand the reasons behind, or the differences between, these two types of particles. Close examination of the dark particles indicates 
$\mathbf{a}$

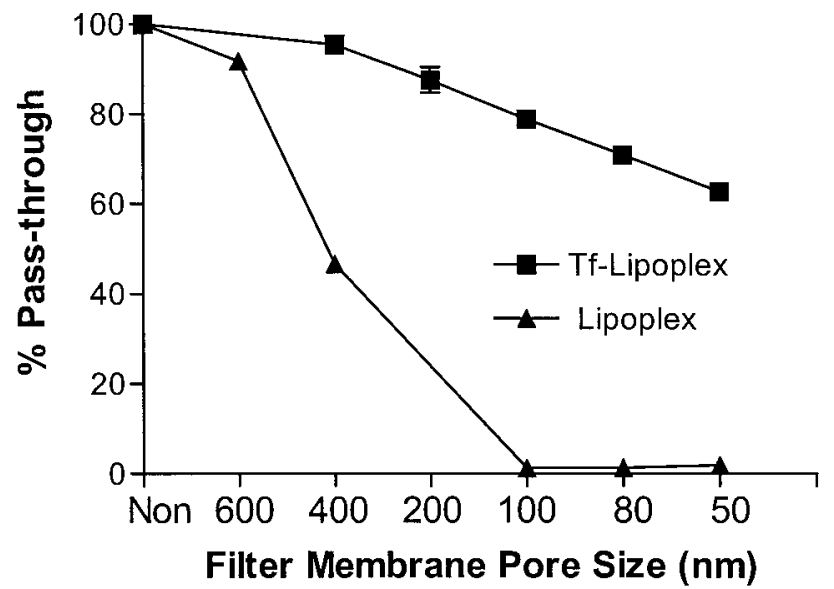

b

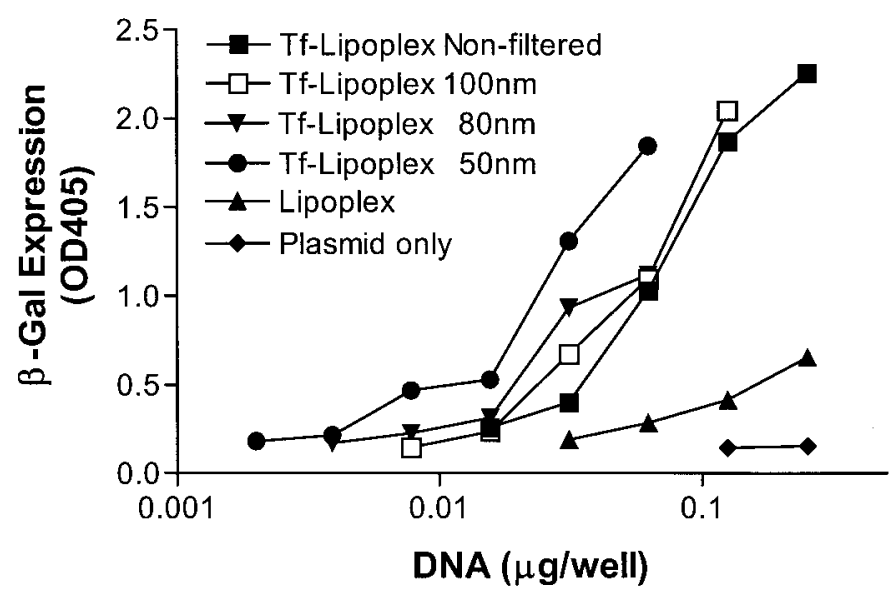

FIG. 4. Effects of Tf-lipoplex particle size on gene transfection efficiency.(a) The percentage of Tf-lipoplex that passes through serial filters, on the basis of DNA concentration, as described in Materials and Methods. The majority of the Tf-lipoplex can pass through the 50- to 80-nm pore size filter. (b) Effect of particle size on transfection activities. DU145 cells in a 96-well plate were transfected with serially filtered Tf-lipoplex containing pCMVb, as described previously (L. Xu et al., 1997, 1999a). Small particles (50-nm pore size filtration) are more efficient than nonfiltered particles, which consist of both small and large particles.

that their structure closely resembles that of a coated virus particle, for example, influenzavirus or herpesvirus. This is the first report demonstrating a self-assembled, ligand-targeted, nonviral vector that closely resembles a virus particle both in architecture and in its uniformly small size. This virus-like compact nanostructure may be the key to their high gene transfer efficiency and efficacy both in vitro and in vivo.

To further analyze the arrangement of the dense core structure of Tf-lipoplex, electron microscopy with negative staining was employed (Perevucnik et al., 1985; Tranum-Jensen, 1988). As shown in Fig. 6, the center of the Tf-lipoplex particle consists of a highly compact, multicentered, ordered onion-like structure, which we call a multicenter lamellar core structure. This lamellar core structure has a periodicity of 6-7 nm (Fig. $6 \mathrm{~d}-\mathrm{i})$. The formation of the Tf-lipoplex particles is quick and efficient (occurring within several minutes) (L. Xu et al., 1999a). The Tf-lipoplex particles are a homogeneous population of small size (50-90 nm) (Fig. 6d-g), whereas the lipoplex particles without $\mathrm{Tf}$ are heterogeneous and much larger, with a greater size range of 100-300 $\mathrm{nm}$ (Fig. 6j). Interestingly, all Tf-lipoplex particles showed similar lamellar core structures on EM observation of negatively stained specimens. This is in contrast to the two populations, light and dark particles, found by cryo-EM, implying that both light and dark particles have the same structure and possibly have the same biological activity. The Tf-lipoplexes containing different sizes of plasmid DNA (e.g., pVec, $4.5 \mathrm{kbp}$; pCMVp53, $6.2 \mathrm{kbp}$; pCMVb, $7.9 \mathrm{kbp}$ ) showed similar size, $\zeta$ potential, and nanostructure. Therefore, at least in the range of 4 to $8 \mathrm{kbp}$, the size of DNA encapsulated is apparently not critical.

\section{Self-assembly process of Tf-Lipoplex}

In an attempt to elucidate the $\mathrm{Tf}$-lipoplex formation process, we mixed Tf-liposome with DNA for 5-20 sec, instead of the usual $15 \mathrm{~min}$, before applying the sample to the grid for EM. 

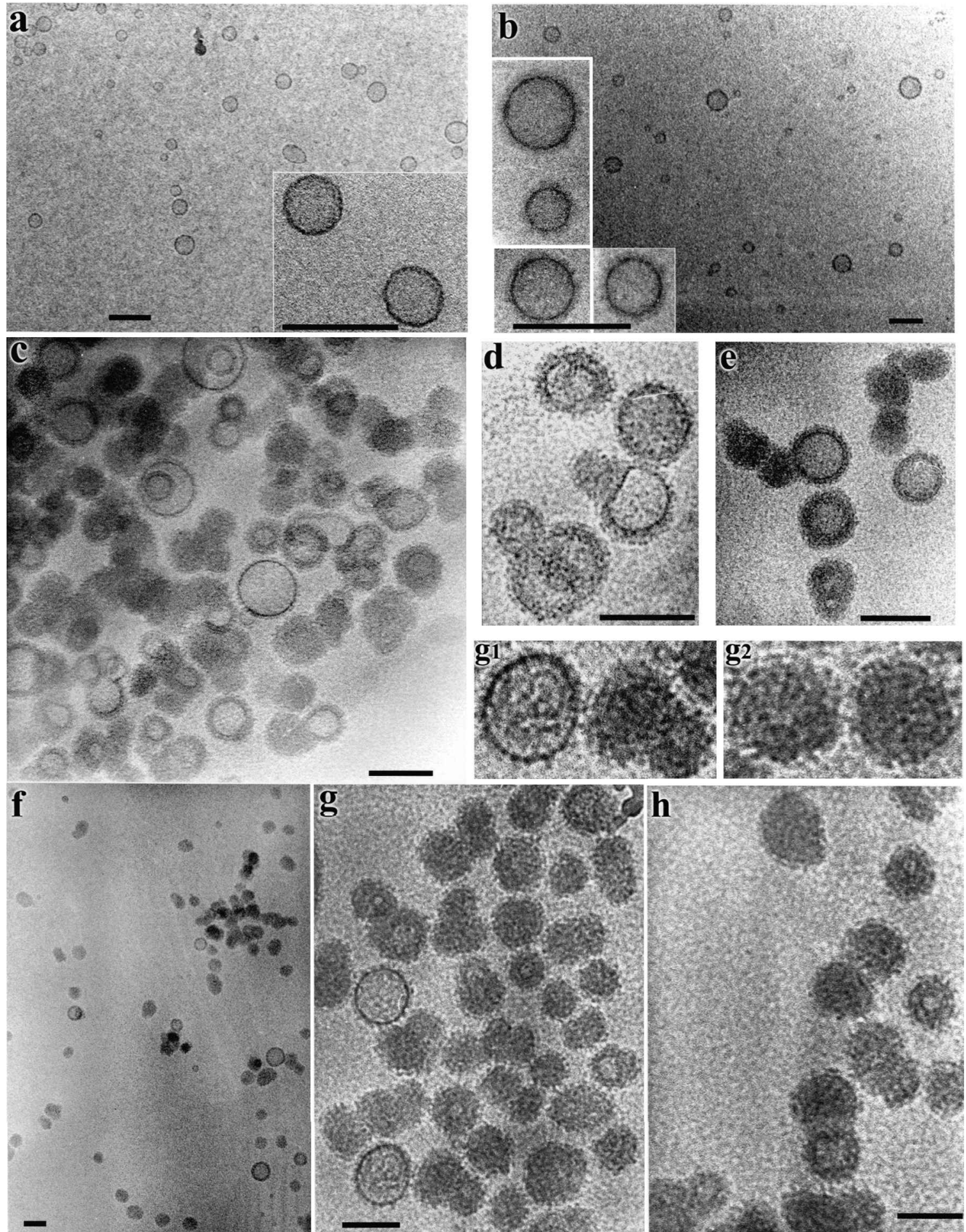

FIG. 5. Cryo-EM analysis of Tf-lipoplex particles. (a) Cationic liposomes (DOTAP:DOPE, 1:1 molar ratio) prepared by the ethanol injection method (L. Xu et al., 2001). (b) Tf-coated liposomes (Tf-Lip). A 2- to 3-nm layer of Tf coating can be seen protruding from the bilayer surface (insets). The size of the liposomes does not significantly change after Tf coating. (c-h) Images of Tf-lipoplex particles prepared from SUVs made either by sonication $(\mathbf{c}-\mathbf{e})$ or by ethanol injection (f-h), according to the optimized in vivo formulation. (d and e) Higher magnification images of (c) with strong defocus to improve the contrast of $\mathrm{Tf}$ spikes. (g1 and g2) Higher magnification images of (g). Tf-lipoplex particles are 50-90 $\mathrm{nm}$ in diameter. Tf-lipoplex has a uniformly condensed core structure surrounded by a Tf-coated membrane, resembling a virus particle. Both dark and light particles can be seen in the preparation. Dark particles are the dominating population. Magnification bars: $100 \mathrm{~nm}$. 

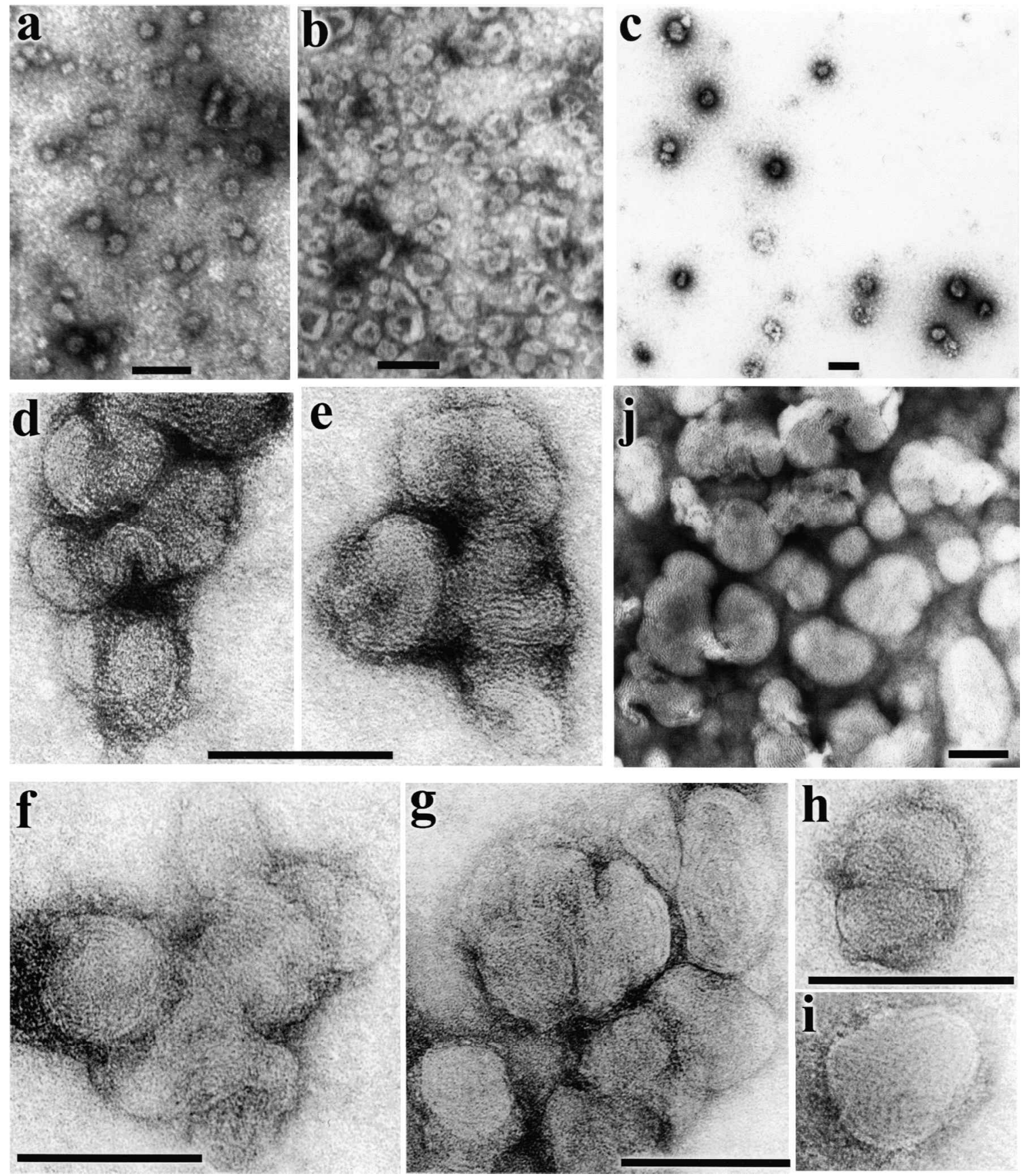

FIG. 6. Negative-stain EM analysis of Tf-lipoplex. (a) Cationic liposomes; (b) Tf-liposome (no DNA); (c) Tf-lipoplex; (d-i) higher magnification images of Tf-lipoplex; (j) lipoplex without Tf. The center of the Tf-lipoplex particle consists of a highly compact, multicentered, ordered onion-like structure, which we call a multicentered lamellar core structure. The lamellar core structure has a periodicity of 6-7 nm. The Tf-lipoplex particles are a homogeneous population of 50-90 nm, whereas the lipoplex particles have a greater size range of 100-300 nm. Magnification bars: $100 \mathrm{~nm}$.

In this way, we observed various steps in complex formation, for example, the stepwise condensation of the DNA chain by Tf-Lip (Fig. 7a). All of these intermediate stages existed simultaneously. Analysis of a large number of images from negatively stained specimens, including those representative of intermediate stages of Tf-lipoplex formation, supplemented by cryo-EM observations, led us to postulate that this multicenter lamellar core structure is formed in a three-step process during the formation of Tf-lipoplex. These steps are shown in both representative EM images (Fig. 7a) and schematic illustration (Fig. 7b). 
Step 1: Several (four to eight or more) Tf-liposome (Tf-Lip) particles come into contact with a DNA molecule, attaching to the DNA strand by electrostatic interaction.

Step 2: The attached Tf-liposome particles condense the DNA to form individual lamellar structures along the DNA strand.

Step 3: The individual lamellar structures condense or fuse to form one larger unit: an ordered and highly compact, onionlike structure, designated as the condensed lamellar core structure. This core is encapsulated by a Tf-coated membrane. The final complex closely resembles a virus particle and is actually smaller than the sum of the four to eight Tf-liposome particles that seem to be involved in the formation of these particles. This is the first indication that each Tf-lipoplex particle seems to be formed via the condensation of one DNA molecule with several cationic liposomes (Fig. 7).

\section{DISCUSSION}

Our results have shown that Tf-lipoplex has (1) a novel virus-mimicking nanostructure, (2) a uniformly small size of $50-90 \mathrm{~nm},(3)$ a neutral surface charge, (4) a multicenter lamellar core structure with a periodicity of 6-7 nm, and (5) is encapsulated by a Tf-coated membrane with Tf molecules protruding as spikes on the surface. These data fit the lamellar $\mathrm{L}_{\alpha} \mathrm{C}$ structure model (Radler et al., 1997; Lasic et al., 1997; Koltover et al., 1998) quite well. Lasic and colleagues (1997) used a combination of cryo-EM and SAXS to examine a lipoplex and found that the lamellar structure has a periodicity (space between lipid bilayers) of $6.5 \mathrm{~nm}$, consistent with the dimensions of a bilayer (4 $\mathrm{nm})$ and a hydrated DNA helix $(2.5 \mathrm{~nm})$. Radler and coworkers (1997) also showed the SAXS pattern of another lipoplex with a clear periodic structure of $6.5-\mathrm{nm}$ spacing. But questions arise when comparing our Tf-lipoplex structure with the reported lipoplex structures, all of which have the lamellar $\mathrm{L}_{\alpha}{ }^{\mathrm{C}}$ structure. How would the Tf-coated cationic liposomes efficiently condense DNA into this virus-mimicking nanostructure? How are Tf molecules involved in the three-step process discussed above?

In general, plasmid DNA is a circular molecule of about 900 $\mathrm{nm}$ (contour length) in the form of a flexible supercoil (Kennedy et al., 2000), strongly depending on salt concentration. At normal low salt concentrations DNA is stiff (persistence length) relative to the size and flexibility of the liposomes. However, Lasic et al. (1997) and Templeton et al. (1997) postulate a condensation and increased flexibility of DNA on interaction with cationic lipid. Our Tf-liposomes are 25-30 $\mathrm{nm}$ in diameter with a $2.5-\mathrm{nm}$ Tf coating. The final condensation in step 3 above is crucial in ensuring formation of the compact, virus-mimicking nanostructure. DNA-induced vesicle rupture and reorganization, as described by Huebner et al. (1999) and Kennedy et al. (2000), may be involved in this step. Tf plays a critical role in this process as well, as, consistent with other reports (Gustafsson et al., 1995; Templeton et al., 1997; Battersby et al., 1998), complexing DNA with cationic liposomes without $\mathrm{Tf}$ forms only large lamellar structures of $150-400 \mathrm{~nm}$, with a strong positive surface charge ( $\zeta$ potential, $+30-35 \mathrm{mV}$ ). In contrast, our Tf-coated cationic liposomes are apparently able to efficiently condense DNA into this virus-mimicking nanostructure, with a size of 50-90 nm and neutral surface charge. We propose that it is this novel structure that is most likely responsible for the high efficiency and efficacy of the systemic tumor-targeted gene delivery.

According to the mathematical models of the lamellar $\mathrm{L}_{\alpha} \mathrm{C}$ structure for lipoplex (Dan, 1997; Harries et al., 1998; Koltover et al., 2000; May et al., 2000), the water gap between lipid bilayers $\left(\delta_{\mathrm{w}}\right)$ is $2.5 \mathrm{~nm}$ and the membrane bilayer thickness $\left(\delta_{\mathrm{m}}\right)$ is $3.5-4.4 \mathrm{~nm}$, depending on the lipid composition. Periodicity (d) equals $\delta_{\mathrm{w}}+\delta_{\mathrm{m}}$ and is 6-7 $\mathrm{nm}$. The space between DNA strands $\left(d_{\mathrm{DNA}}\right)$ is $2.5-5.7 \mathrm{~nm}$, depending on the $+:-$ charge ratio, and the diameter of a hydrated DNA strand $\left(\phi_{\mathrm{DNA}}\right)$ is 2.5 nm. Koltover et al. (2000) described a sharp DNA condensation transition in an isoelectric lipoplex induced by divalent electrolyte counterions, leading to a highly condensed lipoplex. Our cryo-EM shows that Tf-liposomes have a 2.5-nm Tf coating, corresponding to an apparent diameter of the Tf molecule $\left(\phi_{\mathrm{Tf}}\right)$ of $2.5 \mathrm{~nm}$. When Tf-liposomes start to condense DNA (steps 2 and step 3 above; and see Fig. 7a and b), the membrane-bound 2.5-nm Tf molecule fits into the water gap between lipid bilayers $\left(\delta_{\mathrm{w}}\right)$ and the space between DNA strands $\left(d_{\text {DNA }}\right)$. On the basis of our data as well as the lamellar $\mathrm{L}_{\alpha} \mathrm{C}$ models mentioned above, and Koltover's counterion-induced DNA condensation transition model (Koltover et al., 2000), we propose a Tf-facilitated DNA-cocondensation model, as illustrated in Fig. 7c, for the formation of the Tf-lipoplex particle. In the three-step process of Tf-lipoplex formation, Tf molecules play a crucial role in facilitating DNA condensation and lamellar $\mathrm{L}_{\alpha}{ }^{\mathrm{C}}$ structure formation, possibly by fitting in the space between lipid bilayers and DNA strands ( $\delta_{\mathrm{w}}$ and $d_{\text {DNA }}$ ) (Fig. $7 \mathrm{c})$, thus changing the anion-cation charge interaction and energy distribution, similar to Koltover's bivalent counterion (Koltover et al., 2000). The presence of Tf in the $\delta_{\mathrm{w}}$ and $d_{\mathrm{DNA}}$ space could balance the complex to isoelectrical status, which is supported by our observation of the neutral $\zeta$ potential for the Tf-lipoplex. At this isoelectrical status, in the two dimensions between lipid bilayers, the two lobes of the Tf molecule ( $\mathrm{N}$ and $\mathrm{C}$ ), each of which has one $\mathrm{Fe}^{3+}$, might function like a bivalent counterion by fitting into the major groove of two adjacent parallel DNA helixes (Fig. 7c), leading to reversal, from repulsive to attractive, of the electrostatic forces $\left(F_{\mathrm{e}}\right)$ between DNA chains. Thus, a DNA condensation transition could occur, resulting in a highly condensed lamellar core structure wherein $d_{\mathrm{DNA}}<\phi_{\mathrm{Tf}}+\phi_{\mathrm{DNA}}$ (Fig. 7c). Although in-depth studies need to be performed to confirm our hypothesis, we propose that step 3 (described above) may include DNA-induced vesicle rupture and reorganization (Sternberg et al., 1998; Huebner et al., 1999) followed by a Tf-induced DNA condensation transition. One speculation on the possible mechanisms refers to the wrapping of a DNA string around nucleosomes, a natural process a cell uses to manipulate chromosomal DNA (P. Frederik, personal communication). The detailed mechanism of interactions among Tf, lipid bilayers, and DNA at the molecular level still requires more study, and a lamellar to hexagonal phase $\left(\mathrm{L}_{\alpha}{ }^{\mathrm{C}}\right.$ to $\left.\mathrm{H}_{\mathrm{II}}{ }^{\mathrm{C}}\right)$ transition (Koltover et al., 1998, 1999) remains a possibility.

The proposed model is further supported by our observation that reversing the complexing sequence of the three components for Tf-lipoplex from $(\mathrm{Tf}+$ liposome) + DNA to (liposome + 


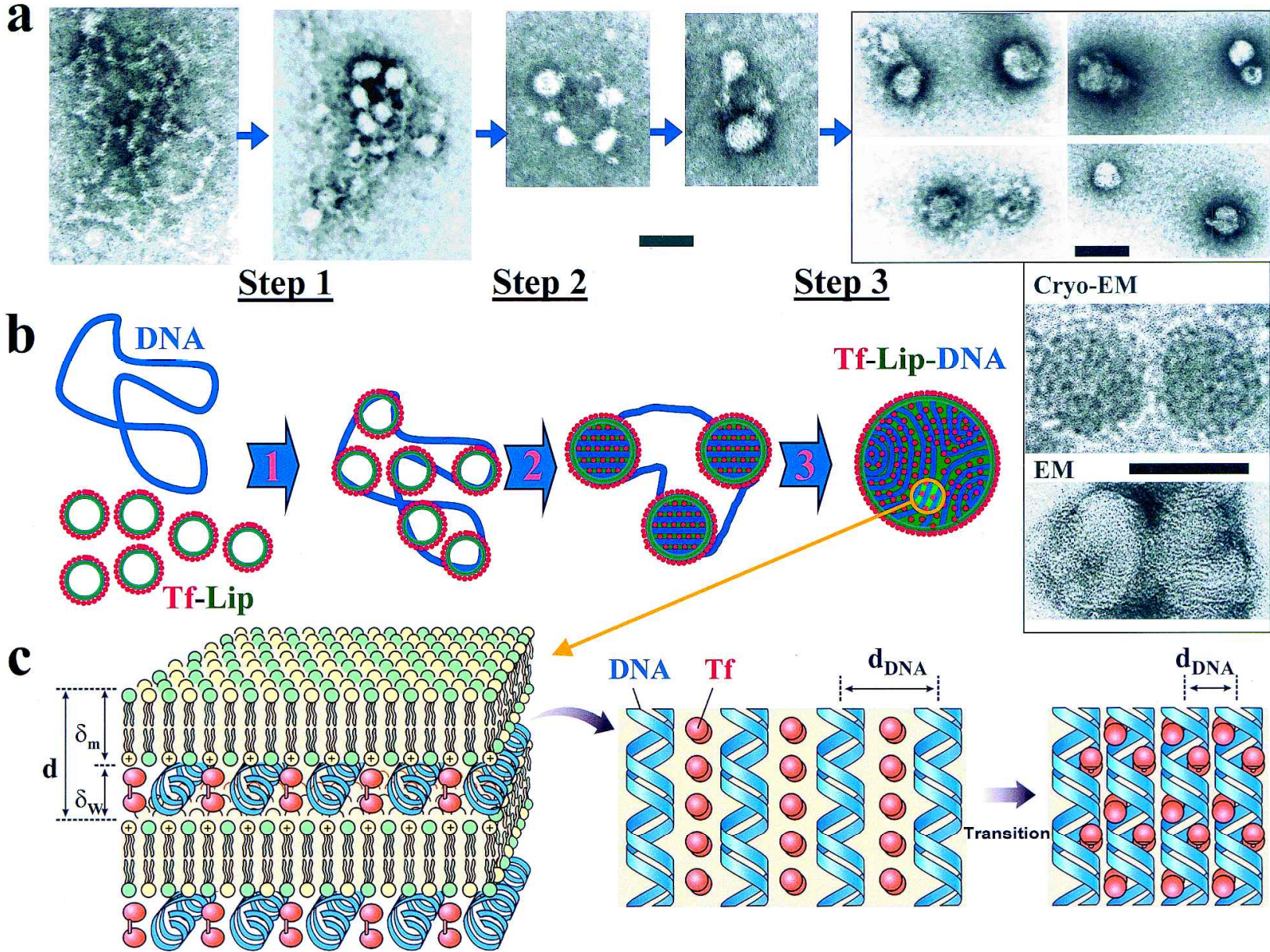

FIG. 7. Three-step process of Tf-lipoplex particle formation and proposed Tf-facilitated DNA cocondensation model. (a) Representative negative-staining EM images of intermediate stages in the Tf-lipoplex formation process. Magnification bar: $100 \mathrm{~nm}$. (b) Schematic illustration of the three-step process of Tf-lipoplex particle formation. Step 1: Several (four to eight or more) Tf-liposomes (Tf-Lip) (Tf, in red; Lip, in green) come into contact with a DNA molecule, attaching to the DNA strand (in blue) by electrostatic interaction. Step 2: The attached Tf-liposomes condense the DNA to form individual lamellar structures along the DNA strand. Step 3: The individual lamellar structures condense or fuse to form an condensed lamellar core structure, encapsulated by a Tf-coated membrane. (c) Illustration of a proposed Tf-facilitated DNA cocondensation model. During step 3, Tf molecules fit into the $\delta_{\mathrm{w}}$ and $d_{\mathrm{DNA}}$ spaces, thus changing the anion-cation charge interaction and energy distribution, balancing the complex to isoelectrical status. At this status, the Tf molecule might function like a counterion by fitting into the major groove of two adjacent parallel DNA helixes, leading to reversal from repulsive to attractive electrostatic forces $\left(F_{\mathrm{e}}\right)$ between DNA chains. Thus, a DNA condensation transition could occur, resulting in a highly condensed lamellar core structure wherein $d_{\text {DNA }}<$ $\phi_{\mathrm{Tf}}+\phi_{\mathrm{DNA}}$. The final complex closely resembles a virus particle and is actually smaller than the sum of the four to eight Tf-liposomes that seem to be involved in the formation of these particles.

DNA) + Tf or (DNA + Tf $)+$ liposome abolished the unique nanostructure and transfection efficiency, consistent with an earlier report (Cheng, 1996). We have also observed that there are some free $\mathrm{Tf}$ molecules present in Tf-liposomes. When we removed free Tf from Tf-liposomes before complexing DNA, we were unable to obtain the same nanostructure with the same size and efficiency (data not shown), indicating that free Tf molecules are important for the DNA-cocondensation process, even though we do not yet understand the precise mechanism(s). On the other hand, free Tf can be removed after Tf-lipoplexes have formed without changing particle size and biological activity. This further supports our model in that, during the DNA-in- duced vesicle rupture and reorganizationproposed in step 3 (described above), the ruptured or reorganized Tf-liposomes have inside membranes without $\mathrm{Tf}$ coating that are now exposed to the outside for further DNA condensing. If free Tf is removed, then, because there is no extra Tf to coat the newly exposed lipid membranes, the spaces between lipid bilayers and DNA strands ( $\delta_{\mathrm{w}}$ and $\left.d_{\mathrm{DNA}}\right)$ will not be filled and, consequently, will not be able to balance the anion-cation interaction and energy distribution. Therefore, there is no electrostatic force reversal for the DNA condensation transition to occur. Another advantage of the presence of free $\mathrm{Tf}$ is that, in step 3 (described above), the reorganized outermost membrane can be coated 
with Tf, which is important for improved stability and also for tumor targeting through binding to the Tf receptor.

Self-assembly of complex systems consisting of basic organic components required for life, such as proteins, lipids, nucleotides, as well as inorganic elements, exists widely in nature (Koltover et al., 2000). However, even in this postgenomic era, we still know little about the mechanisms behind the self-assembly of these complex biosystems. By learning from nature we may be able to mimic these natural bioprocesses to develop better methods for diagnosis, prevention, and treatment of human diseases. The self-assembly of the Tf-lipoplex nanostructure system described in this paper consists of protein (Tf), lipids (cationic liposomes), nucleotides (DNA), and ions $\left(\mathrm{Fe}^{3+}\right)$; mimicks a virus particle in its architecture and defined small size; and shows enhanced stability, improved gene transfer efficiency, and efficacy for systemic p53 gene therapy of human prostate cancer, as well as head and neck cancer, breast cancer, bladder cancer, and other human tumor models (L. Xu et al., 1999a, 2001; and L. Xu and E. Chang, unpublished data). The proposed multistep self-assembly process and protein (Tf)facilitated lipid-nucleotide (DNA) cocondensation model could conceivably exist in the biological world. Somewhat similar bioprocesses may be used by viruses, bacteria, or eukaryotic cells, for example, in nucleosome processing of chromosomal DNA, in mitochondrial DNA, or in hierarchical self-assembly (Wong et al., 2000). It is also likely that other proteins have a function similar to Tf. Functionally Tf-like proteins, peptides, or even polymers (Pitard et al., 1997) could be employed on the basis of this model to develop functional biosystems. Currently, we are examining various protein/peptide ligands to develop similar gene delivery systems on the basis of our proposed model. Better understanding and further refinement of this model may help in the rational design of more efficient and effective targeted molecular therapeutics for various diseases.

\section{ACKNOWLEDGMENTS}

We thank Drs. P. Bomans, A. Rusnock, and M. Dai for expert technical assistance with electron microscopy, and Dr. G. Ertem for plasmid preparation. This work was supported by a grant from the NIH (DE13151-01 to E.H.C.).

\section{REFERENCES}

BATTERSBY, B. J., GRIMM, R., HUEBNER, S., and CEVC, G. (1998). Evidence for three-dimensional interlayer correlations in cationic lipid-DNA complexes as observed by cryo-electron microscopy. Biochim. Biophys. Acta 1372, 379-383.

CHENG, P.W. (1996). Receptor ligand-facilitated gene transfer: Enhancement of liposome-mediated gene transfer and expression by transferrin. Hum. Gene Ther. 7, 275-282.

DAN, N. (1997). Multilamellar structures of DNA complexes with cationic liposomes. Biophys. J. 73, 1842-1846.

DAN, N. (1998). The structure of DNA complexes with cationic liposomes-cylindrical or flat bilayers? Biochim. Biophys. Acta 1369, 34-38.

FENG, D., NAGY, J.A., HIPP, J., PYNE, K., DVORAK, H.F., and DVORAK, A.M. (1997). Reinterpretation of endothelial cell gaps induced by vasoactive mediators in guinea-pig, mouse and rat: Many are transcellular pores. J. Physiol. 504, 747-761.
GUSTAFSSON, J., ARVIDSON, G., KARLSSON, G., and ALMGREN, M. (1995). Complexes between cationic liposomes and DNA visualized by cryo-TEM. Biochim. Biophys. Acta 1235, 305-312.

HARRIES, D., MAY, S., GELBART, W.M., and BEN-SHAUL, A. (1998). Structure, stability, and thermodynamics of lamellar DNAlipid complexes. Biophys. J. 75, 159-173.

HUEBNER, S., BATTERSBY, B.J., GRIMM, R., and CEVC, G. (1999). Lipid-DNA complex formation: Reorganization and rupture of lipid vesicles in the presence of DNA as observed by cryoelectron microscopy. Biophys. J. 76, 3158-3166.

KAWAURA, C., NOGUCHI, A., FURUNO, T., and NAKANISHI, M. (1998). Atomic force microscopy for studying gene transfection mediated by cationic liposomes with a cationic cholesterol derivative. FEBS Lett. 421, 69-72.

KENNEDY, M.T., POZHARSKI, E.V., RAKHMANOVA, V.A., and MACDONALD, R.C. (2000). Factors governing the assembly of cationic phospholipid-DNA complexes. Biophys. J. 78, 1620-1633.

KOLTOVER, I., SALDITT, T., RADLER, J.O., and SAFINYA, C.R. (1998). An inverted hexagonal phase of cationic liposome-DNA complexes related to DNA release and delivery. Science 281, 78-81.

KOLTOVER, I., SALDITT, T., and SAFINYA, C.R. (1999). Phase diagram, stability, and overcharging of lamellar cationic lipid-DNA self-assembled complexes. Biophys. J. 77, 915-924.

KOLTOVER, I., WAGNER, K., and SAFINYA, C.R. (2000). DNA condensation in two dimensions. Proc. Natl. Acad. Sci. U.S.A. 97, 14046-14051.

LASIC, D.D., STREY, H., STUART, M.C.A., PODGORNIK, R., and FREDERIK, P.M. (1997). The structure of DNA-liposome complexes. J. Am. Chem. Soc. 119, 832-833.

LIN, A.J., SLACK, N.L., AHMAD, A., KOLTOVER, I., GEORGE, C.X., SAMUEL, C.E., and SAFINYA, C.R. (2000). Structure and structure-function studies of lipid/plasmid DNA complexes. J. Drug Target. 8, 13-27.

MARSHALL, E. (2000). Gene therapy on trial. Science 288, 951-957. MAY, S., HARRIES, D., and BEN SHAUL, A. (2000). The phase behavior of cationic lipid-DNA complexes. Biophys. J. 78, 1681-1697.

PEREVUCNIK, G., SCHURTENBERGER, P., LASIC, D.D., and HAUSER, H. (1985). Size analysis of biological membrane vesicles by gel filtration, dynamic light scattering and electron microscopy. Biochim. Biophys. Acta 821, 169-173.

PIROLLO, K.F., XU, L., and CHANG, E.H. (2000). Non-viral gene delivery for p53. Curr. Opin. Mol. Ther. 2, 168-175.

PITARD, B., AGUERRE, O., AIRIAU, M., LACHAGES, A.M., BOUKHNIKACHVILI, T., BYK, G., DUBERTRET, C., HERVIOU, C., SCHERMAN, D., MAYAUX, J.F., and CROUZET, J. (1997). Virus-sized self-assembling lamellar complexes between plasmid DNA and cationic micelles promote gene transfer. Proc. Natl. Acad. Sci. U.S.A. 94, 14412-14417.

RADLER, J.O., KOLTOVER, I., SALDITT, T., and SAFINYA, C.R. (1997). Structure of DNA-cationic liposome complexes: DNA intercalation in multilamellar membranes in distinct interhelical packing regimes. Science 275, 810-814.

STERNBERG, B., HONG, K., ZHENG, W., and PAPAHADJOPOULOS, D. (1998). Ultrastructural characterization of cationic liposome-DNA complexes showing enhanced stability in serum and high transfection activity in vivo. Biochim. Biophys. Acta 1375, 23-35.

TEMPLETON, N.S., LASIC, D.D., FREDERIK, P.M., STREY, H.H., ROBERTS, D.D., and PAVLAKIS, G.N. (1997). Improved DNA: Liposome complexes for increased systemic delivery and gene expression. Nature Biotechnol. 15, 647-652.

TRANUM-JENSEN, J. (1988). Electron microscopy: Assays involving negative staining. Methods Enzymol. 165, 357-374.

WONG, G.C., TANG, J.X., LIN, A., LI, Y., JANMEY, P.A., and SAFINYA, C.R. (2000). Hierarchical self-assembly of F-actin and cationic lipid complexes: Stacked three-layer tubule networks. Science 288, 2035-2039. 
XU, L., PIROLLO, K.F., and CHANG, E.H. (1997). Transferrin-liposome-mediated p53 sensitization of squamous cell carcinoma of the head and neck radiation in vitro. Hum. Gene Ther. 8, 467-475.

XU, L., PIROLLO, K.F., TANG, W.H., RAIT, A., and CHANG, E.H. (1999a). Transferrin-liposome-mediated systemic p53 gene therapy in combination with radiation results in regression of human head and neck cancer xenografts. Hum. Gene Ther. 10, 2941-2952.

XU, L., PIROLLO, K.F., RAIT, A., MURRAY, A.L., and CHANG, E.H. (1999b). Systemic p53 gene therapy in combination with radiation results in human tumor regression. Tumor Targeting 4, 92-104.

XU, L., PIROLLO, K.F., and CHANG, E.H. (2001). Tumor-targeted p53 gene therapy enhances the efficacy of conventional chemo/radiotherapy. J. Control. Release 74, 115-128.

XU, Y., HUI, S. W., FREDERIK, P., and SZOKA, F.C., JR. (1999). Physicochemical characterization and purification of cationic lipoplexes. Biophys J. 77, 341-353.
Address reprint requests to: Dr. Esther H. Chang Department of Oncology Lombardi Cancer Center Research Building/E420 Georgetown University Medical Center 3970 Reservoir Road NW Washington, D.C. 20007

E-mail: change@georgetownedu

Received for publication September 14, 2001; accepted after revision January 14, 2002.

Published online: February 1, 2002. 